\title{
EMPREENDEDORISMO E EMPODERAMENTO FEMININO: UMA ANÁLISE DA LITERATURA INTERNACIONAL.
}

Guilherme Primo Matias ${ }^{1}$

Flavia Obara Kai ${ }^{2}$

Fabio Emanuel Farago ${ }^{1}$

${ }^{1}$ Departamento de Administração Geral e Aplicada / PPGADM - Escola de Administração / Universidade Federal do Paraná

2 UFPR Universidade Federal do Paraná 


\section{EMPREENDEDORISMO E EMPODERAMENTO FEMININO: UMA ANÁLISE DA LITERATURA INTERNACIONAL}

Resumo: Neste trabalho discute-se o estado da arte da relação entre o empreendedorismo e o empoderamento feminino por meio de uma revisão sistemática da literatura internacional. $\mathrm{O}$ empreendedorismo da mulher é uma forma de empoderamento fundamental para o desenvolvimento equitativo das sociedades organizadas, promovendo o alívio a pobreza, a melhoria nas condições de vida das famílias e a igualdade entre pessoas. A metodologia utilizada é uma revisão sistemática da literatura internacional, as fontes pesquisadas foram as bases de dados internacionais Scopus, Web of Science e Science Direct. O período investigado foi de 2007 a 2017. Entre as principais contribuições, foi apresentado um panorama sobre os principais objetivos, metodologias utilizadas, noções de empoderamento feminino, principais contribuições dos artigos investigados, e por fim, são apontados caminhos para pesquisas futuras.

Palavras-chave: Empreendedorismo feminino. Mulher. Revisão Sistemática.

\section{Introdução}

O empreendedorismo diz respeito à criação de algo novo e com valor, por meio da dedicação de tempo e esforço, envolvendo riscos sociais, emocionais e financeiros para receber resultados monetários e satisfação pessoal (Hisrich, Michael e Dean, 2005).

Os conceitos referentes ao termo empreendedorismo não mencionam distinções quanto ao gênero, já que as características são encontradas tanto em homens quanto em mulheres, porém, as definições iniciais do termo contemplavam, na maioria das vezes, o sexo masculino. Entretanto, atualmente é notável o crescimento feminino na atividade econômica em diversos países (Strobino e Teixeira, 2014).

Gomes, Santana, Araújo e Martins (2014) afirmam que os primeiros estudos sobre empreendedorismo feminino ocorreram na década de 1970. No início, havia uma preocupação a respeito do perfil, características das empreendedoras, suas motivações e dificuldades, passando para estudos como competências, processo de criação de empresas e acesso a crédito e capital de risco (Gimenez, Ferreira, Ramos, 2017). 
Quando o empreendedorismo é exercido por mulheres, é possível identificar a emocionalidade no estilo gerencial (Machado, 2006). Além disso, uma vez envolvidas no comportamento empreendedor, as mulheres são mais motivadas do que os homens para continuarem desenvolvendo habilidades empreendedoras (Ghouse, McElwee, Meaton e Durrah, 2017).

Em harmonia com Tillmar (2016), o empreendedorismo permite às mulheres a possibilidade de empoderamento econômico e social, porém, ainda existem obstáculos relacionados ao gênero no que diz respeito ao potencial completo que as mulheres podem alcançar. Além disso, o empoderamento das mulheres não deve ser relacionado somente ao empreendedorismo, mas também a políticas públicas e intervenções feministas.

Nesse sentido, o empoderamento da mulher significa sua participação em todos os segmentos de atividades econômicas essenciais, como por exemplo, estabelecer sociedades mais justas e estáveis, melhorar a qualidade de vida de mulheres, homens e comunidades, e construir economias fortes. Além disso, o empoderamento envolve o desenvolvimento socioeconômico para capacitar as mulheres por meio da igualdade de gênero (Kumar e Rakhin, 2016).

Ainda segundo Cappelle, Melo, Brito e Brito (2004), as relações de gênero refletem manifestações de poder e resistência, em campos de disputas sociais. Por isso, refletir sobre teorizações que envolvam o gênero demonstra um desejo de transformação social, podendo ser compreendidas como discursos capazes de mediar contradições nas relações entre sujeitos das organizações.

Desta maneira, para fomentar discussões a respeito do tema, o presente artigo tem por objetivo elaborar uma revisão sistemática de literatura a respeito da interação entre empreendedorismo e o empoderamento feminino. Para tanto, foram consultadas as bases de dados internacionais Scopus, Web of Science e Science Direct no período de 2007 a 2017, de modo a verificar o estado da arte entre os dois temas. Sequencialmente, foram analisados os as definições de empoderamento, metodologias, principais contribuições e pesquisas futuras apontadas nos trabalhos investigados.

\section{Referencial Teórico}

O empreendedorismo feminino, desde o final dos anos 90, tem se caracterizado como um campo de pesquisa bem estabelecido e respeitado, se tornando um tema frequente na mídia e em debates políticos sobre empregabilidade e mercado de trabalho (Minniti e Naudé, 2010). As pesquisas nesse campo, abrangem desde fatores individuais (educação, idade, escolha/motivos para empreender, auto-confiança e características pessoais), até questões no nível meso (tipo de atividade, acesso a financiamento, aspectos legais) e fatores no nível 
sociocultural (normas sociais, interpretações, percepções/concepções sobre o papel da mulher) (Naguib e Jamali, 2015).

$\mathrm{O}$ aumento do empreendedorismo feminino deve-se a uma mudança no comportamento das mulheres, não em termos de se assemelharem aos homens, mas sim para competir igualitariamente com os mesmos (Melo e Lopes, 2012). Foi observado por Machado (2002), que antigamente a mulher era dependente financeiramente do pai ou marido. Atualmente, as mulheres desejam mais do que apenas constituir família, elas procuram construir sua própria identidade, não mais se submetendo as imposições, mas buscando seu próprio caminho e expressando sua criatividade e força de vontade.

O empreendedorismo da mulher, de acordo com Shabana, Khan, Vashistha e Siddique (2017), é um ato de criação de negócios que empodera tanto as forças econômicas como a posição social das mulheres na sociedade. Os autores evidenciam que existe um relacionamento bidirecional entre desenvolvimento econômico e empoderamento feminino. De um lado, o desenvolvimento se manifesta na redução da desigualdade entre homens e mulheres. Por outro lado, o empoderamento feminino facilita o desenvolvimento em função das mulheres possuírem habilidades para trabalhar arduamente e desenvolver ideias inovadoras para construir uma sociedade saudável (Shabana et al., 2017).

Diversos estudos dão suporte ao argumento que o empreendedorismo feminino conduz ao desenvolvimento econômico. O estudo de Lerner, Brush e Hisrich (1997) apontou que as mulheres empreendedoras desempenham um papel substancial no desenvolvimento do setor de pequenas empresas, principalmente em economias em transição. A pesquisa de Minniti (2010) evidenciou que o entendimento e o suporte do comportamento empreendedor nas mulheres têm uma repercussão positiva no bem-estar e na equidade social de um país. A autora aponta esse campo como uma área muito promissora para pesquisas futuras. Minniti e Naudé (2010) apontam que existe uma ligação entre empreendedorismo feminino e criação de valor, emprego, acumulação de capital humano, e entre outros.

No entanto, apesar de a importância destacada do empreendedorismo feminino para as sociedades, foi observado por Lassale e McElwee (2016) que as mulheres empreendedoras enfrentam muitas dificuldades, sobretudo em economias em desenvolvimento. Para os autores, muitas mulheres se tornam empreendedoras pela necessidade para sobreviver ou para melhorar seus meios de subsistência, e podem ser dependentes das oportunidades estruturais que estão disponíveis.

O apoio e suporte das famílias são frequentemente fundamentais para as mulheres poderem empreender e obter sucesso (Brynin e Schupp, 2000). O acesso a conhecimento técnico, habilidades de gerenciamento, inovação e experiencia profissional bem como a disponibilidade desses na sociedade para as mulheres também são fatores que potencializam o empreendedorismo feminino (Sidhu e Kaur, 2006). A educação feminina, seja na expansão dos

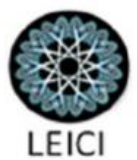


níveis educacionais ou na maior oferta de cursos superiores, é fundamental para as mulheres possam empreender (Melo e Lopes, 2012).

Enquanto todos esses fatores são importantes para o desenvolvimento do empreendedorismo feminino, Minniti e Naudé (2010) apontam que o empoderamento das mulheres, é parte integrante do processo para promover a inserção das mulheres no empreendedorismo, principalmente em países em desenvolvimento. Também foi destacado por Sultana, Jamal e Najaf (2017) que o empoderamento das mulheres é uma questão central tanto para o desenvolvimento do empreendedorismo feminino como dos países ao redor do mundo.

O termo empoderamento tem suas raízes na reforma protestante, iniciada por Lutero no séc. XVI. Usado transitivamente, empoderar significa dar poder a outro, o significado é quase sinônimo de autonomia, que se refere à capacidade do indivíduo e/ou grupos poderem decidir sobre as questões que lhes dizem respeito. A palavra empoderamento originou-se do vocábulo inglês empowerment, cujo termo foi utilizado inicialmente em países de língua inglesa (BAQUERO, 2012).

A partir de então, o termo empoderamento tem sido utilizado em diferentes áreas de conhecimento - educação, sociologia, ciência política, saúde pública, psicologia comunitária, serviço social, administração. O conceito tem sido adotado por governos, organizações da sociedade civil e agências de desenvolvimento direcionadas para a melhoria da qualidade de vida e dignidade humana de setores pobres e responsabilização social (NARAYAN, 2002).

Já o empoderamento feminino, de acordo com Sultana, Jamal e Najaf (2017), é um fenômeno dos anos 90, que significa equipar as mulheres para serem economicamente independentes, com autoestima positiva para as habilitar a enfrentar qualquer situação difícil e para participar ativamente da tomada de decisões. Para Sreenivas e Subramanya (2014), o empoderamento das mulheres é uma combinação do aumento da atividade econômica das mulheres e do controle sobre a renda resultante do acesso a serviços financeiros com melhores habilidades, mobilidade e conhecimento.

De forma semelhante, Kabeer (1999) explica que o empoderamento das mulheres se refere ao processo pelo qual aqueles que foram negados a capacidade de fazer escolhas de vida estratégicas adquirem essas habilidades. Existem diversas dimensões de empoderamento feminino, o trabalho de Fernandes, Lopes, Watanabe, Yamaguchi e Godoi (2016) elaboraram uma categorização com cinco dimensões: econômica, psicológica, sociocultural/educacional, políticas/grupal e familiar. As cinco categorias podem ser observadas no quadro 01:

Quadro 01: Dimensões do Empoderamento Feminino.

\begin{tabular}{|l|l|l|}
\hline Dimensão & \multicolumn{1}{|c|}{ Características } & \multicolumn{1}{|c|}{ Autores } \\
\hline \multirow{3}{*}{ Econômica } & $\begin{array}{l}\text { Mulheres ganham participação por meios de rendas } \\
\text { próprias para produção familiar e controle sobre os } \\
\text { ativos produtivos e bens. }\end{array}$ & $\begin{array}{l}\text { Melo e Lopes, 2012; } \\
\text { Costa, 2008; } \\
\text { Malhotra, 2002. }\end{array}$ \\
\hline
\end{tabular}




\begin{tabular}{|c|l|l|}
\hline Psicológica & $\begin{array}{l}\text { Mulheres apresentam a necessidade de crescer e se } \\
\text { desenvolver por meio da autoconfiança e motivação, } \\
\text { autoestima, bem-estar, senso de aceitação dos direitos. }\end{array}$ & $\begin{array}{l}\text { Lisboa, 2007; } \\
\text { Malhotra, 2002. }\end{array}$ \\
\hline Sociocultural/Educacional & $\begin{array}{l}\text { Grupos de indivíduos capazes de desafiar concepções } \\
\text { culturais agregando valor familiar. }\end{array}$ & $\begin{array}{l}\text { Deere e Léon, 2002; } \\
\text { Malhotra, 2002. }\end{array}$ \\
\hline Políticas e grupal & $\begin{array}{l}\text { Engajamento com posição de autoridade por parte dos } \\
\text { grupos. }\end{array}$ & $\begin{array}{l}\text { Deere e Léon, 2002; } \\
\text { Costa, 2008. }\end{array}$ \\
\hline Familiar & $\begin{array}{l}\text { Envolvimento na capacidade de proteção e apoio à } \\
\text { família. }\end{array}$ & $\begin{array}{l}\text { Melo e Lopes, 2012; } \\
\text { Malhotra, 2002; } \\
\text { Arruda, 1996. }\end{array}$ \\
\hline
\end{tabular}

Fonte: Adaptado de Fernandes et al. (2016).

Segundo os autores, a categoria econômica favorece as mulheres na distribuição de renda igualitária em relação ao gênero masculino. A perspectiva psicológica se relaciona ao desenvolvimento da auto-confiança e motivação nas mulheres. A dimensão politica diz respeito a busca pelo poder social. A categoria familiar afirma sobre o empoderamento do papel da mulher em relação ao homem dentro da família. E a dimensão sociocultural favorece a liberdade da mulher (Fernandes et al., 2016).

\section{Metodologia}

Esta pesquisa possui uma natureza qualitativa. A metodologia utilizada foi uma revisão sistemática da literatura internacional sobre empreendedorismo e empoderamento feminino. A revisão sistemática, de acordo com Galvão, Sawada e Trevizan (2004), é uma que proporciona uma síntese organizada das informações disponíveis a respeito de um problema específico por meio do método científico. Posto isso, a revisão sistemática permite uma análise baseada nas evidências empíricas das investigações sobre o tema da pesquisa.

As fontes pesquisadas para a coleta de artigos sobre empreendedorismo e empoderamento feminino se deu por meio do portal de periódicos da CAPES, utilizando a conta institucional da Universidade Federal do Paraná. A partir do portal de periódicos foram acessadas três bases de dados: Scopus, Web of Science e Science Direct. O período da investigação foi de 2007 a 2017.

A primeira base de dados internacional utilizada foi o sito eletrônico Scopus. Foram definidos os termos "entrepreneurship" e "women empowerment" para busca em títulos de artigos, resumo e palavras-chave. Como critérios de exclusão utilizamos a busca apenas por artigo no período de 2007 a 2017 nas subáreas de "business, management and accounting". Tal busca resultou em 11 achados sendo 2 trabalhos repetidos e 1 que não foi encontrado por não existir o identificador do objeto digital (DOI), resultando o total de 9 artigos lotados a esta base de dados. 
Em seguida a busca se deu junto ao sitio eletrônico Web of Science. Os termos "entrepreneurship" e "women empowerment" foram buscados com o refinamento para tópicos, visto que o tópico envolve o título, resumo e palavra-chave. Outro critério utilizado foi o de busca a artigos no período de 2007 a 2017 nas subáreas "business" e "management", resultando em 4 artigos para a análise.

Visando uma análise mais rica dos dados, foi acionada as buscas em uma terceira base de dados internacional, o sítio eletrônico Science Direct. Assim como nas demais bases de dados consultadas os termos para busca foram "entrepreneurship" e "women empowerment", refinando as buscas para "review article" no período de 2007 a 2017, totalizando 7 artigos encontrados.

O total de artigos encontrado nas três bases de dados internacionais foi de 20 trabalhos. Todavia, após averiguar quatro duplicações, este número caiu para 16. Um segundo corte foi realizado após a leitura dos artigos em busca dos trabalhos que não atendiam diretamente ao tema, onde foram eliminados mais quatro trabalhos, chegando ao montante total de 12 artigos para serem analisados sistematicamente.

Em relação à revisão sistemática, foi utilizada uma adaptação da metodologia de Sarturi, Seravalli e Boaventura (2015), onde as seguintes informações foram levantadas: ano das publicações, título dos artigos, autores e periódicos em que foram publicados. A seguir, no quadro 02 , foi apresentado os artigos selecionados pela revisão sistemática.

Quadro 02: Artigos Selecionados pela Revisão Sistemática.

\begin{tabular}{|c|c|c|c|}
\hline Ano & Título & Autores & Periódico \\
\hline 2010 & $\begin{array}{l}\text { The story of Lijjat: women's entrepreneurship and } \\
\text { empowerment in India }\end{array}$ & Roy; Lahiri-Roy & $\begin{array}{l}\text { The International journal } \\
\text { of knowledge, culture \& } \\
\text { change management }\end{array}$ \\
\hline 2014 & $\begin{array}{l}\text { Institutionalizing Ethics in Institutional Voids: } \\
\text { Building Positive Ethical Strength to Serve Women } \\
\text { Microfinance Borrowers in Negative Contexts }\end{array}$ & $\begin{array}{l}\text { Chakrabarty; } \\
\text { Bass }\end{array}$ & Journal of Business Ethics \\
\hline 2014 & $\begin{array}{l}\text { Women, mining and development: An emerging } \\
\text { research agenda }\end{array}$ & Jenkins & $\begin{array}{l}\text { The Extractive Industries } \\
\text { and Society }\end{array}$ \\
\hline 2015 & $\begin{array}{l}\text { Gender Differences and Entrepreneurship as a Career } \\
\text { Option: An Analysis }\end{array}$ & Soni; Soni & $\begin{array}{l}\text { Pacific Business Revíew } \\
\text { Intemational }\end{array}$ \\
\hline 2015 & $\begin{array}{l}\text { An empirical study on the impact of micro enterprises } \\
\text { on women empowerment }\end{array}$ & $\begin{array}{l}\text { Paramanandam; } \\
\text { Packirisamy }\end{array}$ & $\begin{array}{l}\text { Journal of Enterprising } \\
\text { Communities: People and } \\
\text { Places in the Global } \\
\text { Economy }\end{array}$ \\
\hline 2015 & $\begin{array}{c}\text { Secular and Islamic feminist entrepreneurship in } \\
\text { Turkey }\end{array}$ & Özkazanç-Pan & $\begin{array}{l}\text { Journal of Gender and } \\
\text { Entrepreneurship }\end{array}$ \\
\hline 2016 & $\begin{array}{l}\text { Ex-garment female workers: a new entrepreneurial } \\
\text { community in Mauritius }\end{array}$ & $\begin{array}{l}\text { Kasseeah; } \\
\text { Tandrayen- } \\
\text { Ragoobur }\end{array}$ & $\begin{array}{l}\text { Journal of Enterprising } \\
\text { Communities: People and } \\
\text { Places in the Global } \\
\text { Economy }\end{array}$ \\
\hline 2016 & $\begin{array}{l}\text { Gendering of commercial justice - experience of self- } \\
\text { employed women in urban Tanzania }\end{array}$ & Tillmar & $\begin{array}{l}\text { Journal of Enterprising } \\
\text { Communities: People and }\end{array}$ \\
\hline
\end{tabular}




\begin{tabular}{|c|c|c|c|}
\hline & & & $\begin{array}{l}\text { Places in the Global } \\
\text { Economy }\end{array}$ \\
\hline 2016 & $\begin{array}{l}\text { Kudumbashree: promoting the self-help group model } \\
\text { of empowerment through women entrepreneurship in } \\
\text { kerala - a study. }\end{array}$ & $\begin{array}{l}\text { Kumar; Jasheena. } \\
\text { C.J }\end{array}$ & $\begin{array}{l}\text { Prabandhan: Indian } \\
\text { Journal of Management }\end{array}$ \\
\hline 2016 & $\begin{array}{l}\text { The Current State of Business and Peace in the Gulf } \\
\text { and the Way Forward }\end{array}$ & $\begin{array}{l}\text { Al Abd; Khalifa; } \\
\text { Mahfouz; Vas }\end{array}$ & $\begin{array}{c}\text { Business, Peace and } \\
\text { Sustainable Development }\end{array}$ \\
\hline 2017 & Barriers to rural women entrepreneurs in Oman & $\begin{array}{c}\text { Ghouse; } \\
\text { McElwee; } \\
\text { Meaton; Durrah }\end{array}$ & $\begin{array}{c}\text { International Journal of } \\
\text { Entrepreneurial Behavior } \\
\text { \& Research } \\
\end{array}$ \\
\hline 2017 & $\begin{array}{l}\text { Fuelling women's empowerment? An exploration of } \\
\text { the linkages between gender, entrepreneurship and } \\
\text { access to energy in the informal food sector }\end{array}$ & Groot et al. & $\begin{array}{l}\text { Energy Research \& Social } \\
\text { Science }\end{array}$ \\
\hline
\end{tabular}

Fonte: Elaborado pelos autores com base nos trabalhos consultados.

$\mathrm{Na}$ próxima seção foi apresentado quadros e textos explicativos acerca dos artigos examinados. A análise elaborada apresenta em um primeiro momento um panorama dos artigos investigados, em termos de evolução e regiões geográficas onde foram elaborados, e posteriormente recai sobre a análise das definições de empoderamento feminino, objetivos, metodologias e principais contribuições.

\section{Resultados}

Embora existam bastante trabalhos sobre empreendedorismo feminino, sua relação com o empoderamento feminino tem sido pouco explorada na literatura internacional, evidenciado pela pouca quantidade de artigos encontrados. Esta pesquisa selecionou todos os artigos presentes nas bases de dados para a análise, exceto os duplicados e sem relação com o tema, no período entre 2007 e 2017. A evolução ao longo do tempo dessas pesquisas pode ser observada no gráfico 01 .

Gráfico 01: Evolução dos trabalhos acerca da relação entre empreendedorismo e empoderamento feminino.

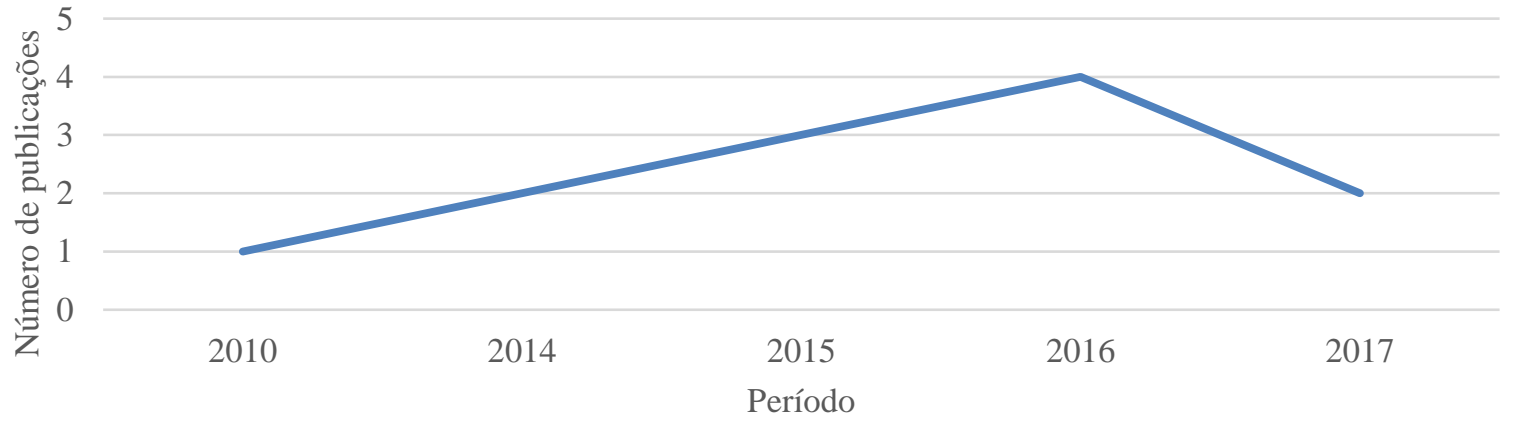

Fonte: Elaborado pelos autores. 
O gráfico sobre os trabalhos desenvolvidos acerca a relação entre empreendedorismo e empoderamento feminino, aponta que houve um crescimento ao longo dos anos que partiu do menor valor observado de 1 artigo em 2010, crescendo até atingir seu maior valor de 4 artigos no ano de 2016, sendo que em 2017 houve uma redução para apenas 2 artigos. Cabe ressaltar que não foram observadas pesquisas, conforme os critérios delineados na metodologia, nos anos de 2007, 2008, 2009, 2011, 2012 e 2013. Já em relação aos países onde a pesquisa foi realizada, os mesmos podem ser observados no gráfico 02 .

Gráfico 02: Países em que as pesquisas foram realizadas.

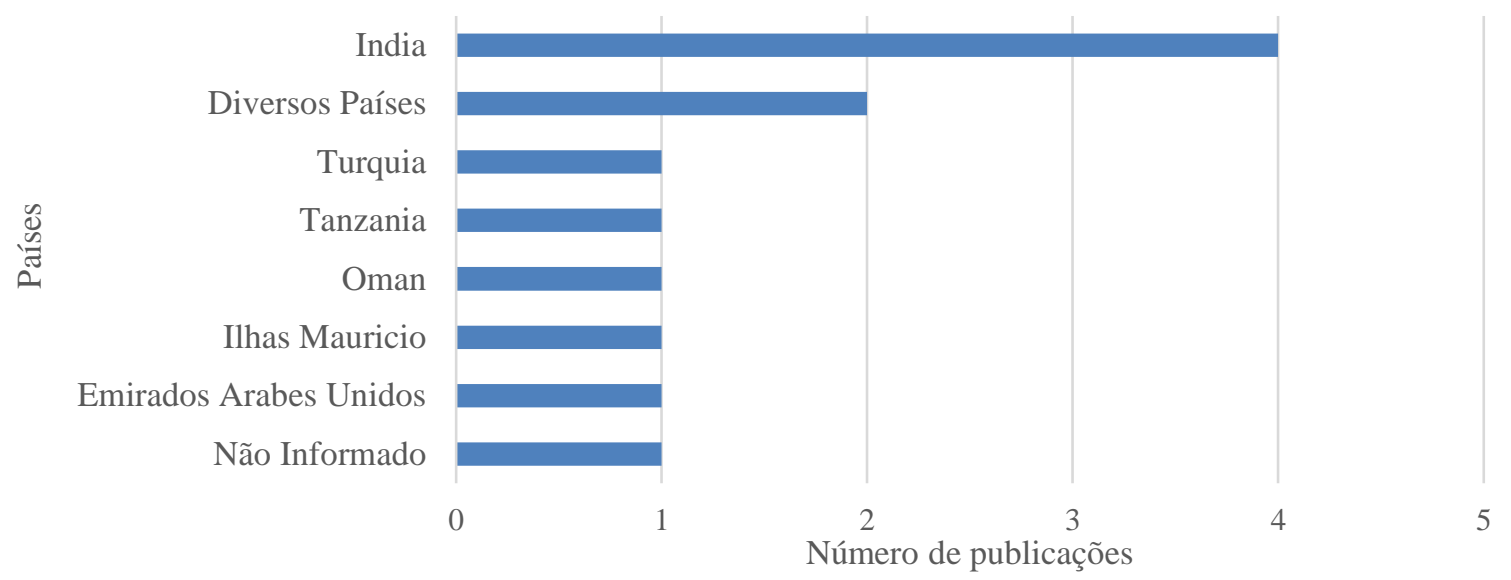

Fonte: Elaborado pelos autores.

O gráfico aponta que maior parte das pesquisas foram elaboradas na Ásia (7 artigos), sendo 4 na Índia, 1 na Turquia, 1 no Omã e 1 nos Emirados Árabes Unidos. Seguido da África (2 artigos), sendo 1 na Tanzânia e 1 nas Ilhas Mauricio. Ressalta-se também que dois trabalhos foram elaborados com dados de diversos países do mundo e um não foi possível identificar.

Em uma análise mais detalhada acerca, foi identificado que uma grande heterogeneidade em termos de dimensões de empoderamento utilizadas, objetivos, meios ou variáveis para identificar o empoderamento feminino, e também em termos de contribuições das pesquisas. Uma síntese com as principais noções de empoderamento feminino adotado, objetivos, meios utilizados e conclusões pode ser observada no quadro 03.

Quadro 03: Panorama dos artigos selecionados a respeito do empreendedorismo e empoderamento feminino. 


\begin{tabular}{|c|c|c|c|c|}
\hline Artigo & Objetivos & Metodologia & $\begin{array}{c}\text { Noção de empoderamento } \\
\text { feminino }\end{array}$ & Principais Contribuições \\
\hline $\begin{array}{c}\text { Al Abd; } \\
\text { Khalifa; } \\
\text { Mahfouz; Vas } \\
\text { (2016) }\end{array}$ & $\begin{array}{l}\text { O artigo analisa o papel dos } \\
\text { negócios na promoção da paz em } \\
\text { regiões vulneráveis a conflitos } \\
\text { por meio de trabalhos de uma } \\
\text { conferência. }\end{array}$ & $\begin{array}{l}\text { O estudo examinou artigos e } \\
\text { discursos dos participantes da } \\
\text { conferência, entrevistaram os } \\
\text { painelistas e tiveram acesso à } \\
\text { base de dados da conferência. }\end{array}$ & $\begin{array}{l}\text { Os autores associam o } \\
\text { empoderamento de minorias ao } \\
\text { empreendedorismo social e à } \\
\text { educação para fomentar a paz em } \\
\text { zonas de conflito. }\end{array}$ & $\begin{array}{l}\text { Foi identificado que as empresas } \\
\text { já demonstram aspectos } \\
\text { favoráveis a programas que } \\
\text { potencializem a paz em países } \\
\text { com conflitos. }\end{array}$ \\
\hline $\begin{array}{l}\text { Chakrabarty; } \\
\text { Bass (2014) }\end{array}$ & $\begin{array}{l}\text { O estudo examina se as } \\
\text { instituições de microfinanças } \\
\text { que atendem as mulheres } \\
\text { mutuarias na BoP adotam um } \\
\text { código de ética organizacional }\end{array}$ & $\begin{array}{l}\text { Foi realizado uma análise } \\
\text { econométrica em instituições de } \\
\text { microfinanças que atendem as } \\
\text { mulheres na base da pirâmide } \\
\text { econômica de todo o mundo. }\end{array}$ & $\begin{array}{lrr}\text { A falta de empoderamento } & \text { em } \\
\text { feminino é refletido em uma } \\
\text { falta de representação das } \\
\text { mulheres nas estruturas de } \\
\text { poder. }\end{array}$ & $\begin{array}{l}\text { As instituições de microfinanças } \\
\text { microfinanças que atendem a } \\
\text { mais mulheres mutuarias são } \\
\text { mais propensas a adotar um } \\
\text { código ética organizacional. }\end{array}$ \\
\hline $\begin{array}{c}\text { Ghouse; } \\
\text { McElwee; } \\
\text { Meaton; Durrah } \\
\text { (2017) }\end{array}$ & $\begin{array}{l}\text { O estudo analisa as barreiras } \\
\text { enfrentadas pelas mulheres } \\
\text { empresárias rurais em Omã. }\end{array}$ & $\begin{array}{l}\text { Análise mista que envolveu } 57 \\
\text { respostas de questionários que, } \\
\text { após categorização resultou em } 5 \\
\text { casos qualitativos apresentados. }\end{array}$ & $\begin{array}{l}\text { Empoderar as mulheres requer } \\
\text { políticas que facilitem e apoiem } \\
\text { potenciais lideranças femininas } \\
\text { empresariais. }\end{array}$ & $\begin{array}{l}\text { Identificou questões não } \\
\text { abordadas na literatura: a } \\
\text { importância da sazonalidade e o } \\
\text { papel dos cônjuges na jornada. }\end{array}$ \\
\hline $\begin{array}{l}\text { Groot et al. } \\
\quad(2017)\end{array}$ & $\begin{array}{l}\text { O artigo explora as ligações } \\
\text { entre o acesso à energia, o } \\
\text { empoderamento das mulheres e } \\
\text { o empreendedorismo. }\end{array}$ & $\begin{array}{l}\text { É feita uma análise da literatura } \\
\text { explorando as ligações entre o } \\
\text { acesso à energia, o } \\
\text { empoderamento das mulheres. }\end{array}$ & $\begin{array}{l}\text { O empoderamento feminino } \\
\text { depende de recursos e } \\
\text { habilidades dos mercados. }\end{array}$ & $\begin{array}{l}\text { O acesso à serviços para } \\
\text { mulheres no setor de alimentos } \\
\text { aumenta a sustentabilidade e } \\
\text { controle das operações. }\end{array}$ \\
\hline Jenkins (2014) & $\begin{array}{l}\text { O estudo evidencia a relação da } \\
\text { mulher e a mineração } \\
\text { explorando como elas são } \\
\text { afetadas pela expansão das } \\
\text { indústrias extrativas. }\end{array}$ & $\begin{array}{l}\text { Revisão bibliográfica nas áreas: } \\
\text { as mulheres trabalhando em } \\
\text { minas; os impactos de gênero na } \\
\text { mineração; mudança de papéis e } \\
\text { desigualdades de gênero. }\end{array}$ & $\begin{array}{l}\text { A autora não apresentou } \\
\text { definição de empoderamento } \\
\text { feminino. }\end{array}$ & $\begin{array}{l}\text { O estudo estabelece as bases } \\
\text { para agenda de pesquisa que visa } \\
\text { colocar as mulheres no centro } \\
\text { das análises das indústrias } \\
\text { extrativas. }\end{array}$ \\
\hline $\begin{array}{l}\text { Kasseeah; } \\
\text { Tandrayen- } \\
\text { Ragoobur } \\
\quad(2016)\end{array}$ & $\begin{array}{l}\text { O trabalho investiga as } \\
\text { características dos ex- } \\
\text { trabalhadores de vestuário que se } \\
\text { voltaram para o trabalho } \\
\text { independente. }\end{array}$ & $\begin{array}{l}\text { Análise quantitativa de } 92 \text { ex- } \\
\text { trabalhadoras, que se tornaram } \\
\text { empreendedoras, guiadas pela } \\
\text { necessidade, e atualmente } \\
\text { trabalham por conta própria. }\end{array}$ & $\begin{array}{l}\text { O empoderamento feminino é } \\
\text { definido como o aprimoramento } \\
\text { de sua posição e poder social } \\
\text { (Nachimuthu e Gunatharan, } \\
\text { 2012). }\end{array}$ & $\begin{array}{l}\text { O estudo coloca na vanguarda as } \\
\text { mudanças industriais e as } \\
\text { estratégias individuais de } \\
\text { enfrentamento. }\end{array}$ \\
\hline
\end{tabular}

Organizadores:

- fov eaesp
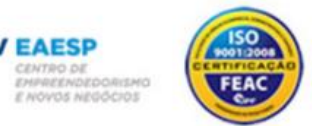
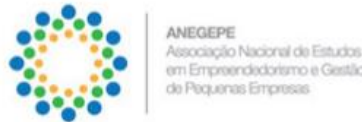
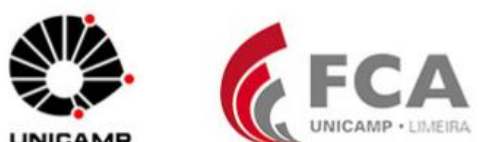

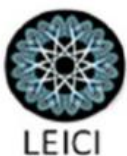




\begin{tabular}{|l|r|r|}
\hline XEGEPE & $\begin{array}{r}\text { Encontro de Estudos sobre Empreendedorismo } \\
\text { e Gestão de Pequenas Empresas }\end{array}$ & $\begin{array}{r}\text { São Paulo/SP } \\
04 \text { a } 06 \text { de julho } \\
\text { de } 2018\end{array}$ \\
\hline
\end{tabular}

\begin{tabular}{|c|c|c|c|c|}
\hline $\begin{array}{l}\text { Kumar; } \\
\text { Jasheena. } \\
\text { (2016) }\end{array}$ & $\begin{array}{l}\text { O objetivo foi explorar por meio } \\
\text { de um grupo, a forma como estas } \\
\text { estimulam o empoderamento das } \\
\text { mulheres e o empreendedorismo. }\end{array}$ & $\begin{array}{l}\text { Estudo de dois casos: (1) } \\
\text { empoderamento da mulher; }(2) \\
\text { experimentos de empresa. Em } \\
\text { diversas funções de uma } \\
\text { comunidade feminina. }\end{array}$ & $\begin{array}{l}\text { Empoderar as mulheres significa } \\
\text { dar participação completa na } \\
\text { vida econômica, em todos os } \\
\text { níveis. }\end{array}$ & $\begin{array}{l}\text { Foi demonstrado os benefícios } \\
\text { do modelo de grupos de } \\
\text { autoajuda de empoderamento em } \\
\text { mulheres empreendedoras. }\end{array}$ \\
\hline $\begin{array}{c}\text { Özkazanç-Pan } \\
(2015)\end{array}$ & $\begin{array}{l}\text { Este artigo pretende destacar as } \\
\text { abordagens feministas seculares } \\
\text { e islâmicas para o } \\
\text { empreendedorismo como meio } \\
\text { para desafiar a desigualdade de } \\
\text { gênero no contexto turco. }\end{array}$ & $\begin{array}{l}\text { Foi utilizada duas organizações } \\
\text { de mulheres, e as atividades } \\
\text { empreendedoras desenvolvidas } \\
\text { pelas mulheres desafiam as } \\
\text { normas patriarcais, valores e } \\
\text { práticas na sociedade Turca. }\end{array}$ & $\begin{array}{l}\text { A autora define o } \\
\text { "empreendedorismo como uma } \\
\text { forma de empoderamento } \\
\text { feminino", como uma forma de } \\
\text { mudar normas e estruturas } \\
\text { culturais patriarcais enraizadas. }\end{array}$ & $\begin{array}{l}\text { Por meio do envolvimento com o } \\
\text { empreendedorismo, a ideologia } \\
\text { feminista representa um } \\
\text { compromisso ético-político para } \\
\text { desmantelar as ideologias } \\
\text { neoliberais no contexto turco. }\end{array}$ \\
\hline $\begin{array}{l}\text { Paramanandam; } \\
\text { Packirisamy } \\
\text { (2015) }\end{array}$ & $\begin{array}{l}\mathrm{O} \text { artigo visa identificar se as } \\
\text { microempresas levam ao } \\
\text { empoderamento } \\
\text { empreendedorismo feminino. }\end{array}$ & $\begin{array}{l}\text { Análise documental por meio de } \\
\text { dados primários coletados em } \\
\text { escritórios e secundários por } \\
\text { meio de amostragem. }\end{array}$ & $\begin{array}{l}\text { O empoderamento das mulheres } \\
\text { é aquele que leva a uma boa } \\
\text { família, boa sociedade e uma boa } \\
\text { nação. }\end{array}$ & $\begin{array}{l}\text { As mulheres estão atreladas ao } \\
\text { desenvolvimento econômico, } \\
\text { com implicações } \\
\text { sustentabilidade. }\end{array}$ \\
\hline $\begin{array}{l}\text { Roy; Lahiri- } \\
\text { Roy (2010) }\end{array}$ & $\begin{array}{l}\text { Este artigo tem por objetivo } \\
\text { narrar a história de uma } \\
\text { organização indiana de sucesso, } \\
\text { para mulheres, chamada de Lijat. }\end{array}$ & $\begin{array}{lll}\text { O artigo identifica } & \text { o } \\
\text { empoderamento por meio } & \text { de } \\
\text { narrativas das mulheres } & \text { na } \\
\text { organização indiana Lijat. } & \end{array}$ & $\begin{array}{l}\text { O empoderamento ocorre nos } \\
\text { membros quando lhes é dado um } \\
\text { meio de participação, associado } \\
\text { a um sentimento de } \\
\text { pertencimento a um grupo. }\end{array}$ & $\begin{array}{l}\text { O modelo de negócios da Lijat } \\
\text { fornece soluções para criar } \\
\text { capital social, combater a } \\
\text { pobreza e empoderar as } \\
\text { mulheres e suas famílias. }\end{array}$ \\
\hline $\begin{array}{l}\text { Soni; Soni } \\
\text { (2015) }\end{array}$ & $\begin{array}{l}\text { O trabalho explora a mentalidade } \\
\text { da geração jovem em relação ao } \\
\text { empreendedorismo e a } \\
\text { inclinação ao gênero. }\end{array}$ & $\begin{array}{l}\text { O estudo teve caráter descritivo } \\
\text { e, por meio de questionário } \\
\text { estruturado, foi analisada a } \\
\text { dependência } \\
\text { empreendedorismo e gênero. }\end{array}$ & $\begin{array}{l}\text { O empoderamento da mulher é } \\
\text { relacionado com a } \\
\text { empreendedorismo, pois auxilia } \\
\text { no bem-estar socioeconômico. }\end{array}$ & $\begin{array}{l}\text { A inclinação } \\
\text { empreendedorismo não depende } \\
\text { do gênero. Estudantes homens e } \\
\text { mulheres são igualmente } \\
\text { atraídos para empreender. }\end{array}$ \\
\hline Tillmar (2016) & $\begin{array}{l}\text { O artigo discute a justiça } \\
\text { comercial por uma perspectiva } \\
\text { de gênero no empreendedorismo } \\
\text { da Tanzânia. }\end{array}$ & $\begin{array}{l}\text { Mulheres empreendedoras foram } \\
\text { entrevistadas. Houve } \\
\text { categorização dos temas e foram } \\
\text { encontrados padrões sobre a } \\
\text { percepção da justiça comercial. }\end{array}$ & $\begin{array}{l}\text { O empoderamento feminino } \\
\text { permite avanço econômico e } \\
\text { social também por meio de } \\
\text { intervenções políticas. }\end{array}$ & $\begin{array}{l}\text { As mulheres casadas têm mais } \\
\text { facilidade de alcançar justiça } \\
\text { comercial, mas devido ao } \\
\text { favorecimento dos negócios ao } \\
\text { gênero masculino as outras não. }\end{array}$ \\
\hline
\end{tabular}

Fonte: Elaborado pelos autores com base nos trabalhos consultados.

Organizadores:

- fov EAESP
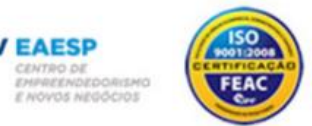
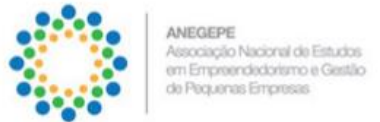

Realizadores:
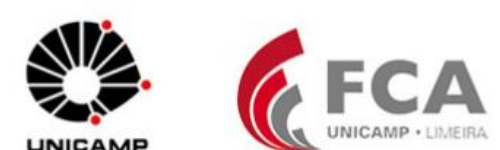

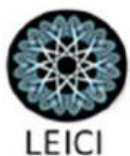


Apreciando a definição acerca do empoderamento feminino dos trabalhos analisados, é possível destacar que o empoderamento da mulher exige uma participação em algum grupo social de modo que a empreendedora exerce uma posição social (Roy; Lahiri-Roy, 2010; Kasseeah; Tandrayen-Ragoobur, 2016). Nota-se que uma vez que a mulher é empoderada, ela pode se tornar empreendedora e por meio disto, ela pode gerar um bem-estar socioeconômico não só a ela, mas também a sua família, comunidade e sociedade (Soni; Soni, 2015).

Todavia, Chakrabarty e Bass (2014), salientam que a falta de representatividade da mulher nas estruturas de poder é um fator que limita o desenvolvimento do empoderamento feminino. De modo que para reverter esta situação é preciso remodelar normas e regras existentes na sociedade moderna, bem como a alteração no modelo de estruturas patriarcais enraizadas na sociedade (Özkazanç-Pan, 2015).

Nessa conformidade Tillmar (2016) e Ghouse et al. (2017), acenam para a formulação de políticas capazes de suprir essa falta de representatividade das mulheres junto as estruturas de poder bem empodera-las. Tal atitude demonstrará um avanço socioeconômico (Kumar; Jasheena, 2016), onde toda a sociedade é favorecida, pois, o avanço do empoderamento feminino depende de recursos e habilidades de mercados globais (Groot et al., 2017), de maneira que o empoderamento feminino favorece a promoção da paz em contextos de conflitos (Al Abd et al., 2016).

Em relação ao tipo de estudo, é possível identificar que a relação entre empreendedorismo e empoderamento feminino é predominantemente qualitativa. A maioria (cinco artigos) apresenta natureza qualitativa, seguido por artigos quantitativos (três), mistos (dois) e de revisão bibliográfica (dois). Isso se deve predominante aos problemas de pesquisa e objetivos darem ênfase a aspectos subjetivos e específicos da mulher, e sua relação com o contexto.

No que diz respeito aos participantes dos estudos, encontram-se: mulheres, painelistas, estudantes e representantes de organizações apoiadoras de mulheres. Além disso, os artigos não apresentam detalhadamente os instrumentos de validação e confiabilidade dos resultados obtidos. É importante salientar que outras variáveis foram analisadas, além do empoderamento e empreendedorismo da mulher, mas que se relacionam com o tema, como, por exemplo: a discriminação, as diferenças socioeconômicas, a busca pela paz em regiões de conflito, a religião, o acesso à energia e a sustentabilidade.

Outrossim, os artigos analisados elucidam que existe a necessidade da ampliação de estudos científicos sobre o item em evidência. Quanto a que grande parte dos artigos descreverem o contexto indiano, clarifica-se a oportunidade que novos trabalhos relacionados têm de explorarem mais o avanço de políticas públicas, não se limitando apenas aos níveis de análise micro organizacional e individual.

Nota-se também que o fator nível de formação pode ser crucial na ascensão do empoderamento feminino bem como no desenvolvimento de uma sociedade mais justa. Novos estudos que relacionem a promoção à educação as minorias com o empoderamento/empreendedorismo feminino tocaria não só o desenvolvimento das mulheres, mas também das famílias, das comunidades, e de toda a sociedade.

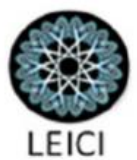


Com base nos estudos de Fernandes et al. (2016), o empoderamento feminino dos artigos analisados podem ser classificados em dimensões econômicas, psicológicas, socioculturais/educacionais, políticas/grupais e familiar. Nesse sentido, é possível identificar que a dimensão grupal, ou seja, o engajamento dos grupos por posições de autoridade, assim como a dimensão econômica e sociocultural são mais evidenciadas, seguida da dimensão psicológica na qual as mulheres almejam o desenvolvimento pela autoconfiança e a familiar.

Adicionalmente, destaca-se que o artigo de Groot et al. (2017) não se enquadra em nenhuma das dimensões de empoderamento já descritas, pois, para os autores, o empoderamento está mais atrelado com a obtenção de recursos. Esse fato justifica-se devido ao contexto da pesquisa, caracterizado pela falta de acesso a serviços e recursos essenciais.

\section{Conclusão}

Como considerações finais, cabe ressaltar a pequena quantidade de estudos sobre empreendedorismo e empoderamento feminino que foram encontrados nas bases selecionadas. Atenta-se desta forma para a importância de mais pesquisas sobre o tema, pois, as contribuições dos artigos investigados evidenciam a relevância destacada do empreendedorismo e empoderamento da mulher para a promoção do desenvolvimento econômico e social, combate à pobreza, criação de capital social, igualdade entre homens e mulheres e para o bem-estar das famílias.

Foi observado também um relativo alto grau de heterogeneidade nas pesquisas, em termos de objetivos, metodologias, dimensões de empoderamento feminino e contribuições. Enquanto alguns artigos se utilizam de abordagens qualitativas, como a história de vida, outros se utilizam de modelos quantitativos e econométricos. Os artigos também se diferenciam em termos de entendimento do empoderamento feminino e os fatores que levam a isto, que variam desde o sentimento de participação e pertencimento até uma forma de mudar as estruturas sociais.

A partir da análise dos artigos, diversas possibilidades relevantes de pesquisas futuras podem destacadas, entre elas, (1) mais pesquisas que explorem as experiências individuais das mulheres com o empreendedorismo com seu contexto institucional; (2) modelos de negócios de sucesso apontando como eles permitem o empoderamento e sua influência no desenvolvimento da sociedade onde está inserido; (3) pesquisar empiricamente a multiplicidade de maneiras pelas quais o empoderamento ocorre, bem como os entraves a este; (4) mapear os padrões do ambiente por meio do qual o empreendedorismo e o empoderamento feminino se desenvolve.

Entre as limitações da presente pesquisa, pode-se citar a utilização de apenas três bases de dados internacionais. Apesar do esforço para selecionar as principais bases de dados, ao impor este corte os autores potencialmente eliminaram artigos que poderiam dar insights e contribuições teóricas importantes. Outra limitação diz respeito ao termos utilizados, de modo que termos similares também poderiam conter trabalhos relevantes ao tema. 


\section{Referencias}

Baqueiro, R.V.A. (2012). Empoderamento: Instrumento de emancipação social? Uma discussão conceitual. Revista Debates, v. 6, n.1 p. 173-187, 2012.

Brynin, M.; Schupp, J. (2000). Education, employment and gender inequality amongst couples. European Sociological Review, Vol. 16 No. 4, pp. 249-265.

Cappelle, M.; Melo, M.; Brito, M.; Brito, M. (2004). Uma Análise da Dinâmica do Poder e das Relações de Gênero no Espaço Organizacional. In: RAE-eletrônica. São Paulo: v. 3, n. 2.

Fernandes, T. S.; Lopes, G. S. C.; Watanabe, M.; Yamaguchi, C. K.; Godoi, C. K. (2016). Dimensões do empoderamento feminino: autonomia ou dependência? Revista Alcance Eletrônica - vol. 23 - n. 3 - jul./set. 2016.

Galvão, C. M.; Sawada, N. O.; Trevizan, M. A. (2004). Revisão Sistemática: Recurso que Proporciona a Incorporação das Evidências na Prática da Enfermagem. Revista LatinoAmericana de Enfermagem, v. 12, n. 3, p. 549-556.

Ghouse, S.; McElwee, G.; Meaton, J.; Durrah, O. (2017) Barriers to rural women entrepreneurs in Oman. Entrepreneurial Behavior \& Research, https://doi.org/10.1108/IJEBR-02-2017-0070. Ghouse, S.; Mcelwee, G.; Meaton, J.; Durrah, O. (2017). Barriers to rural women entrepreneurs in Oman. International Journal of Entrepreneurial Behavior \& Research.

Gimenez, F.A.P.; Ferreira, J.M.; Ramos, S.C. (2017). Empreendedorismo feminino no Brasil: gênese e formação de um campo de pesquisa. Revista de empreendedorismo e gestão de pequenas empresas. v.6., n.1., p.40-74.

Gomes, A. F., Santana, W. G. P., Araújo, U. P.; Martins, C. M. F. (2014). Empreendedorismo Feminino como Sujeito de Pesquisa. Revista Brasileira de Gestão de Negócios, 16(51): 319342.

Hisrich, R. D; Michael, P. P.; Dean, A. S. (2005). Entrepreneurship. 6 ed. New York: McGrawHill Irwin.

Kabeer, N. (1999). Resources, agency, achievements: reflections on the measurement of women's empowerment. Development and Change, Vol. 30 No. 3, pp. 435-464.

Kumar, A.; Rakhin, J. (2016). Kudumbashree: Promoting the Self-Help Group Model of Empowerment Through Women Entrepreneurship in Kerala - A Study.

Lassale, P.; McElwee, G. (2016). Polish entrepreneurs in glasgow and entrepreneurial opportunity structure. International Journal of Entrepreneurial Behaviour \& Research, Vol. 22 No. 2, pp. 260-281.

Lerner, M.; Brush, C.; Hisrich, R. (1997). Israeli women entrepreneurs: an examination of factors affecting performance. Journal of Business Venturing, Vol. 12 No. 4, pp. 315-339. 
Machado, H. P. V. (2002). Identidade empreendedora de mulheres no Paraná. (Tese de doutorado). Programa de Pós-Graduação em engenharia de produção. Universidade Federal de Santa Catarina. UFSC.

Machado, H.V. (2006). Expressão emocional no exercício da atividade empreendedora por mulheres. Revista Organizações \& Sociedade. v.13, n. 38.

Melo, M. C. O. L.; Lopes, A. L. M. (2012). Empoderamento de mulheres gerentes: a construção de um modelo teórico de análise. Revista Gestão e Planejamento, v. 12, n. 3, p. 648-667.

Minniti, M,; Naudé, W. (2010). What Do We Know about the Patterns and Determinants of Female Entrepreneurship across Countries? European Journal of Development Research, vol. 22, 3, 277-293.

Minniti, M. (2010). Female Entrepreneurship and Economic Activity. European Journal of Development Research, 22, 294-312.

Naguib, R.; Jamali, D. (2015). Female entrepreneurship in the UAE: a multi-level integrative lens. Gender in Management: An International Journal, vol. 30, no. 2, 2015.

Narayan, D. (2002). Empoderamiento y redución de la pobreza: libro de consulta. Coimbra: World Bank, Alfa Ômega.

Sarturi, G; Seravalli, C; Boaventura, J. M. G. (2015). Afinal o que é distribuir valor para os stakeholders? Uma análise bibliográfica sobre o tema. Rev. Adm. UFSM, Santa Maria, v. 8, Ed. Especial XVI ENGEMA, p. 92-113.

Shabana; Khan, A.; Vashistha, N.; Siddique, R. A. (2017). Women Empowerment through Entrepreneurship for their Holistic Development. Asian Journal of Research in Business Economics and Management, vol. 7, no. 2, pp. 1-17.

Sidhu, K.; Kaur, S. (2006). Development of entrepreneurship among rural women. Journal of Social Science, Vol. 13 No. 2, pp. 147-157.

Sreenivas, N.; Subramanya, S. V. V. (2014). Role of Women Empowerment in Human Development - A study of Select Self-Help Groups. Asian Journal of Research in Business Economics and Management, volume : 4, issue : 8 .

Strobino, M.R.C.; Teixeira, R.M. (2014). Empreendedorismo feminino e o conflito trabalhofamília: um estudo de multicascos no setor de comércio de material de construção da cidade de Curitiba. Revista de Administração de São Paulo, v.49, n.1, p.59-76.

Sultana, H. Y.; Jamal, M. A.; Najaf, D. E. (2017). Impact of Microfinance on Women Empowerment Through Poverty Alleviation: An Assessment of Socioeconomic Conditions in Chennai City of Tamil Nadu. Asian Journal For Poverty Studies, 3(2): 175 - 183.

Tillmar, M. (2016). Gendering of commercial justice - experience of self-employed women in urban Tanzania. Journal of Enterprising Communities: People and Places in the Global Economy, v. 10.

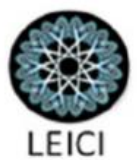

